\title{
Physical activity in out of school hours care: an observational study
}

\author{
Ruth K. Crowe ${ }^{1,2,3^{*}}$, Yasmine C. Probst ${ }^{3}$, Rebecca M. Stanley ${ }^{3,4}$, Sarah T. Ryan ${ }^{4}$, R. Glenn Weaver ${ }^{5}$, \\ Michael W. Beets ${ }^{5}$, Jennifer A. Norman ${ }^{3,6}$, Susan E. Furber ${ }^{3,6}$, Cecilia Vuong ${ }^{7}$, Megan L. Hammersley ${ }^{3,4}$, \\ Karen Wardle ${ }^{7}$, Lisa Franco ${ }^{3,6}$, Marc Davies ${ }^{8}$, Christine Innes-Hughes ${ }^{8}$ and Anthony D. Okely ${ }^{3,4}$
}

\begin{abstract}
Background: Opportunities for physical activity within out of schoolhours care $(\mathrm{OSHC})$ are not well documented in Australia. This study explored factors associated with children (5-12 years) meeting 30 min of moderate to vigorous physical activity (MVPA) while attending OSHC in the afternoon period.

Methods: A cross-sectional study, conducted in 89 OSHC services in New South Wales, Australia, serving 4,408 children. Each service was visited twice between 2018-2019. Physical activity promotion practices were captured via short interviews and System for Observing Staff Promotion of Physical Activity and Nutrition (SOSPAN). Physical activity spaces was measured $\left(\mathrm{m}^{2}\right)$ and physical activity of 3,614 child days (42\% girls), were collected using Acti-Graph accelerometers. Association between program practices and children accumulation of MVPA was tested using mixed effects logistic regression, adjusted by OSHC service and child.
\end{abstract}

Results: Twenty-six percent of children $(n=925)$ accumulated 30 min or more of MVPA. Factors associated with children reaching MVPA recommendations included: services scheduling greater amounts of child-led free play, both 30-59 min (OR 2.6, 95\% Cl 1.70, 3.98) and $\geq 60 \mathrm{~min}(\mathrm{OR} 6.4,95 \% \mathrm{Cl} 3.90,10.49)$; opportunities for staff-led organised play of $\geq 30$ min (OR $2.3,95 \% \mathrm{Cl} 1.47,3.83)$; and active games that engaged the majority of children $(\mathrm{OR} 1.7,95 \% \mathrm{Cl}$ $1.11,2.61)$. Children were less likely to meet MVPA recommendations if services played games with elimination components (OR 0.56, 95\% Cl 0.37, 0.86).

Conclusion: Improvements to service-level physical activity promotion practices, specifically the type of physical activity scheduled and the structure of games, may be an effective strategy to increase MVPA of children attending OSHC afterschool in NSW, Australia.

Keywords: Physical activity, Physical activity environment, MVPA, Out of school hours care, Afterschool care, Child care, Primary-school children

\section{Introduction}

Moderate-to-vigorous physical activity (MVPA) is a vital part of a healthy lifestyle. Regular engagement in MVPA during childhood has not only been associated with numerous physical health outcomes including the

\footnotetext{
*Correspondence: rc101@uowmail.edu.au

${ }^{1}$ Early Start, Building 21, Ring Road, Keiraville, NSW 2522, Australia

Full list of author information is available at the end of the article
}

protection against non-communicable diseases (e.g. type 2 diabetes mellitus, cardiovascular disease), and disease risk factors (e.g. high blood pressure and high cholesterol, overweight and obesity), [1] it is also associated with positive social and emotional health implications (e.g. reduced depression and anxiety) [2]. Like many countries, Australia recommends children accumulate a minimum of 60 min of MVPA each day [3], however, only original author(s) and the source, provide a link to the Creative Commons licence, and indicate if changes were made. The images or other third party material in this article are included in the article's Creative Commons licence, unless indicated otherwise in a credit line to the material. If material is not included in the article's Creative Commons licence and your intended use is not permitted by statutory regulation or exceeds the permitted use, you will need to obtain permission directly from the copyright holder. To view a copy of this licence, visit http://creativecommons.org/licenses/by/4.0/. The Creative Commons Public Domain Dedication waiver (http://creativeco mmons.org/publicdomain/zero/1.0/) applies to the data made available in this article, unless otherwise stated in a credit line to the data. 
1 in 4 Australian children (aged 5-12 years) are meeting this recommendation [3].

With the vast majority of a child's school day spent sedentary, the afterschool period (15:00 -18:00 h) has been identified as a key time for children to accumulate up to half (30 min) of their recommended daily MVPA [4-6]. Out of school hours care (OSHC), under which sits afterschool care, is the second largest childcare setting in Australia, with more than 450,000 children attending each year [7]. However, device-measured physical activity (accelerometry) within OSHC is not well documented in Australia. Therefore, this study aimed to a) describe the physical activity environments in OSHC; b) explore factors associated with children meeting $30 \mathrm{~min}$ of MVPA while attending OSHC in the afterschool time period; and c) determine MVPA levels of children while attending OSHC.

\section{Methods}

\section{Participants and setting}

A total of 243 OSHC services were registered on the Australian Children's Education and Care Quality Authority (ACECQA) website, in 2017, at the time recruitment commenced. OSHC services were eligible to participate in the study if they a) provided care to primary-school aged children (Kindergarten to $6^{\text {th }}$ grade) b) operated during afterschool hours (15:00 - 18:00 h), c) were located within the Illawarra Shoalhaven or South Western Sydney Local Health Districts in New South Wales, Australia, and d) had more than five students enrolled per day. Once the eligibility criteria were applied, a total of 161 OSHC services were contacted for recruitment. Written informed consent was obtained by each OSHC director. All parents/ guardians had the ability to optout (passive consent) their children from the research at any time. The study was advertised to staff, parents and guardians, for a minimum of two weeks prior to the study commencement and throughout the data collection period. Advertisement consisted of several methods; including a) recruitment video and electronic participant information sheets/ opt-out forms were disseminated by each respective OSHC service to all families and employees; b) research notification posters, were displayed at each OSHC entrance, sign in/ out desks and on notice boards; and c) participant information sheets and optout forms were available at each sign in/out areas. All children were invited to wear an accelerometer while in attendance at the OSHC, unless parents/ guardians had opted their child out. All children were given the option to refuse their assent on the day of data collection $[6,8]$. Ethical approval was granted by the University of Wollongong Human Research Ethics Committee (HE17/490). A brief description of the study procedures are provided below and a detailed protocol has been published elsewhere [8].

\section{Physical Activity Measurements}

Child physical activity was objectively measured using Acti-Graph GT3X + model( ActiGraph Corporation, Pensacola, FL) accelerometers, initialised at a sampling rate of $30 \mathrm{Hertz}$. Upon arrival at the OSHC, children were fitted with an accelerometer, worn around the waist sitting at the right-hip. The time accelerometers were fitted was recorded (time-on) and child demographics (school grade and sex) were also collected. As children departed the service, data collectors, stationed near the exit, removed the device and recorded the time (timeoff). A valid day of accelerometry data was defined as a child wearing the accelerometer for at least $60 \mathrm{~min}$ while in attendance at a service $[9,10]$.

\section{Physical activity policies and practices}

Physical activity policies and practices were initially captured via short, structured interviews with the service directors. The interview questions were guided by the validated Healthy Afterschool Activity and Nutrition Document (HAAND) tool [11] and captured information on service policies and practices, including: a) the presence of a physical activity policy, b) staff training, c) the use of physical activity promotion materials, d) the inclusion of children's voices when planning daily programs (children's feedback), and e) the use of recreational screen-time (TV and handheld devices e.g. tablets/ smart phones).

The System for Observing Staff Promotion of Physical Activity and Nutrition (SOSPAN) [12] was used to capture physical activity promotion practices and behaviours, including the type and structure of physical activity opportunities within OSHC programs [12, 13]. In brief, each service was visited, unannounced, on two non-consecutive days by trained data collectors between March 2018 - April 2019. The data were captured via continuously scanning, from left to right, in all rooms and zones consisting of five or more children and at least one staff member. Data collectors systematically rotated between zones, performing a minimum of five scans in each zone before moving into a different area. Scans were continuously completed from the commencement of the session until the end of the program or until less than five children remained at the service. Physical activity behaviours were coded as either: a) free play, which consisted of children playing in an unstructured manner with no direction or input from adults/ staff, b) organised play, usually involving structured games or activities with rules directed by staff (e.g. softball, dodgeball or stuck in the mud), and c) enrichment, a non-physical activity (e.g. 
reading, craft, quiet-play, or homework) typically performed indoors. Other behaviours captured, included: a) the level of staff interaction (i.e. supervising only, engaging in physical activity, encouraging physical activity or leading/ instructing an activity), b) if games were able to engage a majority of the children, c) stand and wait time (i.e. were children lining-up and waiting their turn to play in a game), or d) elimination games (i.e. were participants eliminated from a game when they were deemed "out").

\section{Available physical activity space}

Indoor and outdoor spaces, accessible to children, were identified by staff prior to data collection. Designated areas were divided into zones and identified as physical activity areas (eg. open fields, basketball courts, fixedequipment) or non-physical activity areas (classrooms, halls) and measured (metre ${ }^{2}$ ) using a Craftright measuring wheel by data collectors.

\section{Observer training and reliability}

Data collectors were trained over a three-day period, using a combination of classroom simulations and field practice prior to the study commencement. Data collectors were required to meet $>80 \%$ interrater-reliability via an interval-by-interval agreement on two consecutive days prior to data collection. Reliability scans were collected on each data collection day, with a minimum of $30 \%$ of scans used to calculate reliability [14]. Interraterreliability was calculated using percentage agreement and Cohen's Kappa [15]. The median percentage agreement was $91 \%$ and a Kappa coefficient of 0.97 (ranging from 0.81 to 1.00$)$.

\section{Statistical analysis}

All accelerometry data was downloaded in 15-s epochs from ActiLife software and physical activity levels were calculated in Python software using Evenson cut-points $[16,17]$. All descriptive means, standard deviations, frequencies, percentages and independent $\mathrm{t}$-tests were calculated using SPSS software (v26, IBM Corporation, Armonk, NY, USA). All physical activity practices and behaviours were coded dichotomously, as either observed/reported or not observed/reported. The accumulated time (minutes) spent in various activity types (free-play, organised play and screen-time) were calculated using Excel software and the predefined activity categories and time stamping captured within the SOSPAN instrument. The association between program practices and children meeting $30 \mathrm{~min}$ of MVPA was tested using mixed effects logistic regression, adjusted by OSHC service and child. The mixed effects logistic regression was conducted using STATA software (V. 15.1, College
Station, TX). Statistical analysis was completed in February 2021.

\section{Results}

Of the 161 eligible OSHC services contacted, 89 participated (55\%). Seventy-four (83\%) services were located on school grounds, nine (10\%) in early childhood settings, five $(6 \%)$ in community centres and one $(1 \%)$ in a faithbased location. On average, sessions ran for $180( \pm 16.8)$ minutes and provided opportunities for children to be physically active for $97( \pm 41.1)$ minutes of the session. A total of 4,408 children attended the services, with 3,614 children wearing an accelerometer for a minimum of $60 \mathrm{~min}$ on at least one observation day. Children spent an average of $70.6( \pm 23.5)$ minutes in total physical activity and $22( \pm 12.8)$ minutes in MVPA/day (Table 1$)$. Boys spent significantly more time in MVPA and less time sedentary $(p<0.001)$ than girls.

A total of 9,218 SOSPAN scans were completed across 178 observation days. The percentage of time spent in different activities comprised: $52 \%$ physical activity (38\% child-led free play and 15\% staff-led organised play), $43 \%$ enrichment, and $4 \%$ afternoon snack. Staff supervised children $98 \%$ of the time, engaged in physical activity with children $9 \%$ of the time, and instructed or led physical activities $11 \%$ of the time. A total of $26 \%$ of children met the criterion of $30 \mathrm{~min}$ or more of MVPA. Children who attended services that provided a combination of child-led free play with staff-led organised play spent significantly more time in MVPA than those services which only offered free play or organised play opportunities (Table 2).

Services that provided opportunities for $30-59 \mathrm{~min}$ $(\mathrm{OR}=2.6$; $95 \% \mathrm{CI} 1.7-4.0)$, or more than $60 \mathrm{~min}$ of childled free play $(\mathrm{OR}=6.4 ; 95 \% \mathrm{CI} 3.9-10.5) ; 30 \mathrm{~min}$ or more of scheduled staff-led organised play $(\mathrm{OR}=2.3 ; 95 \% \mathrm{CI}$ 1.5-3.8); or facilitated games which engaged the majority of children (OR $=1.7$; 95\%CI 1.1-2.6), were more likely to have children meet $30 \mathrm{~min}$ of MVPA while attending OSHC services (Table 3). Services that played games with children that included an elimination component were less likely to meet the recommended $30 \mathrm{~min}$ of MVPA than those that did not $(\mathrm{OR}=0.6$; 95\% CI 0.4-0.9). The presence of a physical activity policy, staff training, the use of physical activity promotion material, recreational screen-time, incorporating child activity preferences, stand and wait games and staff engaging in physical activity with children were not associated with children meeting 30 min of MVPA while at the OSHC service. 
Table 1 Sedentary and physical activity levels of children attending Out of School Hours Care (OSHC) services in the afterschool period

\begin{tabular}{|c|c|c|c|c|c|c|c|}
\hline \multirow[b]{2}{*}{ Physical activity levels } & \multirow[b]{2}{*}{$\begin{array}{l}\text { Minutes } \\
\text { Mean (SD) }\end{array}$} & \multirow[b]{2}{*}{$\begin{array}{l}\text { Minutes } \\
\text { Mean (SD) }\end{array}$} & \multirow[b]{2}{*}{ Std. Err } & \multirow[b]{2}{*}{$\begin{array}{l}\text { Minutes } \\
\text { Mean (SD) }\end{array}$} & \multirow[b]{2}{*}{ Std. Err } & \multicolumn{2}{|c|}{ Independent t-test } \\
\hline & & & & & & Sig & $95 \% \mathrm{Cl}$ \\
\hline \multicolumn{8}{|c|}{ Mean time (minutes) spent sedentary and in physical activity levels } \\
\hline & All children $(n=3614)$ & Girls $(n=1521)$ & & Boys $(n=1514)$ & & & \\
\hline Sedentary & $36.0(19.5)$ & $41.1(19.8)$ & 0.51 & $31.1(18.0)$ & 0.46 & $<.001$ & $-11.38,-8.68$ \\
\hline Light physical activity & $48.4(16.3)$ & $48.5(16.2)$ & 0.42 & $49.3(16.7)$ & 0.43 & .148 & $-0.31,2.04$ \\
\hline $\begin{array}{l}\text { Moderate-to-vigorous physical } \\
\text { activity }\end{array}$ & $22.1(12.8)$ & $18.5(10.9)$ & 0.28 & $25.7(13.6)$ & 0.35 & $<.001$ & $6.38,8.14$ \\
\hline \multirow[t]{2}{*}{ Total physical activity } & $70.6(23.5)$ & $67.0(22.5)$ & 0.58 & $75.0(24.0)$ & 0.62 & & \\
\hline & & Grade $K-2(n=1709)$ & & Grade $3-6(n=1326)$ & & & \\
\hline Sedentary & & 33.9 (18.6) & 0.45 & $38.8(20.5)$ & 0.56 & .001 & $-6.33,-3.54$ \\
\hline Light physical activity & & $49.6(18.0)$ & 0.43 & $46.2(16.5)$ & 0.45 & $<.001$ & $2.86,5.20$ \\
\hline $\begin{array}{l}\text { Moderate-to-vigorous physical } \\
\text { activity }\end{array}$ & & $22.4(12.8)$ & 0.31 & $21.7(12.7)$ & 0.35 & .167 & $-0.27,1.57$ \\
\hline Total physical activity & & $73.2(23.6)$ & 0.57 & $68.4(23.4)$ & 0.64 & & \\
\hline \multicolumn{8}{|c|}{ Mean percentage (\%) of wear time spent sedentary and in physical activity levels } \\
\hline & All children $(n=3614)$ & Girls $(n=1521)$ & & Boys $(n=1514)$ & & & \\
\hline Sedentary & $33.5(15.5)$ & $37.7(15.1)$ & 0.39 & $29.1(14.5)$ & 0.37 & $<.001$ & $-9.76,-7.65$ \\
\hline Light physical activity & $45.5(10.3)$ & $45.0(10.4)$ & 0.27 & $46.4(10.2)$ & 0.26 & $<.001$ & $0.75,2.22$ \\
\hline $\begin{array}{l}\text { Moderate-to-vigorous physical } \\
\text { activity }\end{array}$ & $21.0(11.4)$ & $17.2(9.5)$ & 0.25 & $24.5(11.8)$ & 0.30 & $<.001$ & $6.50,8.00$ \\
\hline \multirow[t]{2}{*}{ Total physical activity } & $66.5(15.5)$ & $62.2(15.1)$ & 0.38 & $70.9(14.5)$ & 0.37 & & \\
\hline & & Infant $(n=1709)$ & & Primary $(n=1326)$ & & & \\
\hline Sedentary & & $31.5(15.0)$ & 0.36 & $35.9(15.7)$ & 0.43 & $<.001$ & $-5.54,-3.35$ \\
\hline Light physical activity & & $47.3(10.1)$ & 0.24 & $43.5(10.2)$ & 0.28 & $<.001$ & $3.05,4.50$ \\
\hline $\begin{array}{l}\text { Moderate-to-vigorous physical } \\
\text { activity }\end{array}$ & & $21.1(11.4)$ & 0.28 & $20.5(11.2)$ & 0.31 & .109 & $-0.15,1.48$ \\
\hline Total physical activity & & $68.5(14.9)$ & 0.36 & $64.1(15.7)$ & 0.43 & & \\
\hline
\end{tabular}

Note: Missing descriptive (sex, age group) data of 579 children

Bolded values are significant $P<0.05$

$K-2$ : kindergarten to year 2; Grade 3-6: years 3-6

\section{Discussion}

This study examined the physical activity (PA) levels and environments in a large sample of Australian OSHC services, operating in the hours after school, and the relationship between physical activity practices and staff behaviours on children's physical activity levels. We found that children spent an average of $22 \mathrm{~min}$ in MVPA, with boys accumulating significantly more MVPA than girls. These findings are similar to international studies conducted in comparable settings, in the United States and Norway [18-21]. Although, sedentary time was much higher within the international literature; a recent meta-analysis exploring physical activity and sedentary behaviours in structured settings, found children attending after school programs (ASPs) spent an average of $54.5 \mathrm{~min} / \mathrm{d}$ [18] sedentary compared to $36 \mathrm{~min} /$ day, within our study. These differences may be attributed to international afterschool programs having longer periods of scheduled sedentary-based activities, including: mandatory cultural studies [19] or allocated homework time [13, 20, 22, 23], compared to Australian OSHC [24]. Although homework and craft-based sedentary activities were offered within our sample, they did not occur at structured time intervals nor were they mandatory.

Across all observation days, 26\% of children accumulated $30 \mathrm{~min}$ or more of MVPA. Results from the mixed effects logistic regression indicated that the odds of children accumulating $30 \mathrm{~min}$ of MVPA increased by 6.4 when services provided $60 \mathrm{~min}$ or more of childled free play and 2.3 times when services scheduled at least $30 \mathrm{~min}$ of structured, staff-led organised play into 
Table 2 Characteristics of reported and observed practices, environments and accumulated child physical activity across Out of School Hours Care (OSHC) services

\begin{tabular}{|c|c|c|c|c|}
\hline Reported Program Practices (Short interview) & & Freq & $\%$ & Mean (SD) \\
\hline Written physical activity policy & & 20 & 22 & \\
\hline Physical activity promotion training by a certified training & & 26 & 29 & \\
\hline Physical activity promotion material used & & 18 & 20 & \\
\hline Children's voices and preferences are included in daily programming & & 87 & 97 & \\
\hline \multicolumn{5}{|l|}{${ }^{b}$ Available Physical Activity Space $\left(\mathrm{m}^{2}\right)$} \\
\hline Outdoor & & & & $3,616.6(3182.7)$ \\
\hline Indoor & & & & $70.3(98.3)$ \\
\hline Observed Physical Activity Practices & & 178 & 100 & \\
\hline \multicolumn{5}{|l|}{ Child-led free play } \\
\hline & $<29 \min$ & 40 & 22 & \\
\hline & $30-59 \mathrm{~min}$ & 54 & 30 & \\
\hline & $>60 \mathrm{~min}$ & 83 & 46 & \\
\hline \multicolumn{5}{|l|}{ Staff-led organised play } \\
\hline & None & 98 & 55 & \\
\hline & $<29 \min$ & 34 & 19 & \\
\hline & $>30 \min$ & 41 & 23 & \\
\hline \multirow[t]{2}{*}{ Recreational screen-time } & & 55 & 30 & \\
\hline & $>30 \mathrm{~min}$ & 34 & 19 & \\
\hline Recreational handheld devices (i-pads, tablets, smart-phones) & & 54 & 30 & \\
\hline Active games that engage the majority of children & & 46 & 25 & \\
\hline Active games consisting of elimination components & & 46 & 25 & \\
\hline Child stand and wait games & & 15 & 8 & \\
\hline Staff engage in physical play & & 104 & 58 & \\
\hline Homework & & 45 & 25 & \\
\hline \multicolumn{5}{|c|}{$\begin{array}{l}{ }^{d} \text { Mean minutes of moderate-to-vigorous physical activity (MVPA) accumulated in different } \\
\text { activities types }\end{array}$} \\
\hline Child-led free play only & & 1869 & 52 & $21.5(12.8)$ \\
\hline Staff-led organised play & & 119 & 3 & $16.3(10.5)$ \\
\hline Both free play and organised play & & 1573 & 44 & $24.0(12.6)$ \\
\hline None & & 52 & 1 & $8.2(8.0)$ \\
\hline$\%$ of children meeting $30 \mathrm{~min}>M V P A$ & & & & Pearson's Chi Square \\
\hline Total children & & 925 & 26 & \\
\hline aboys $(n=1514)$ & & 546 & 15 & $p<.001$ \\
\hline${ }^{a}$ Girls $(n=15,521)$ & & 235 & 6.5 & \\
\hline${ }^{\text {a }}$ Grade K-Year $2(n=1709)$ & & 453 & 12 & p.366 \\
\hline${ }^{\text {a }}$ Grade 3 - Year $6(n=1326)$ & & 327 & 9 & \\
\hline
\end{tabular}

Note: Bolded values are significant $\mathrm{P}<0.05$

${ }^{\text {a }}$ Missing descriptive (sex, age) data of 579 children

${ }^{\mathrm{b}}$ Measured on site, in metres using a craft.right measuring wheel

c Physical activity data collected using Actigraph wGT3X-BT model accelerometers

their program. Child-led free play has been recognised throughout the literature as an effective activity type for eliciting high levels of MVPA [20, 22, 25]. However, given the autonomous nature of free-play, it is likely that not all children will choose to engage in active play during this time, therefore organised structured activities may be an important activity to incorporate within the OSHC settings to maximise participation; this could engage a wider range of children, especially girls [26]. The odds of children meeting $30 \mathrm{~min}$ of MVPA further increased by 1.7 times when organised activity included games that engaged the majority of children. Given that organised staff-led activities were observed on less than half of observation days and only a quarter of activities included 
Table 3 Association of Out of School Hours (OSHC) service physical activity promotion practices on child attainment of more than 30 min of moderate-to-vigorous physical activity (MVPA) in the afterschool period

\begin{tabular}{|c|c|c|c|}
\hline Physical Activity Promotion Practices & OR & $95 \% \mathrm{Cl}$ & Pvalue \\
\hline \multicolumn{4}{|l|}{ Physical activity policy } \\
\hline No (Ref) & - & - & - \\
\hline Yes & 1.0 & $(0.65,1.55)$ & 0.968 \\
\hline \multicolumn{4}{|l|}{ Staff training in physical activity promotion } \\
\hline No (Ref) & - & - & - \\
\hline Yes & 1.3 & $(0.94,1.96)$ & 0.102 \\
\hline \multicolumn{4}{|l|}{ Use of physical activity promotion material } \\
\hline No (Ref) & - & - & - \\
\hline Yes & 1.0 & $(0.49,2.11)$ & 0.953 \\
\hline \multicolumn{4}{|c|}{ Recreational screen-time available (TV, movies, computer, video games) } \\
\hline No (Ref) & - & - & - \\
\hline Yes & 0.8 & $(0.54,1.07)$ & 0.121 \\
\hline \multicolumn{4}{|c|}{ Recreational handheld devices (i-pad, phones, Tablet) available } \\
\hline No (Ref) & - & - & - \\
\hline Yes & 0.7 & $(0.50,1.02)$ & 0.069 \\
\hline \multicolumn{4}{|c|}{ Children's voices and activity preferences are included in daily programming } \\
\hline No (Ref) & - & - & - \\
\hline Yes & 1.1 & $(0.29,4.00)$ & 0.905 \\
\hline \multicolumn{4}{|l|}{ Scheduled time for child-led free play } \\
\hline$\leq 29 \min (\operatorname{Ref})$ & - & - & - \\
\hline$(30-59 \mathrm{~min})$ & 2.6 & $(1.70,3.98)$ & $>0.001$ \\
\hline$\geq 60 \mathrm{~min}$ & 6.4 & $(3.90,10.49)$ & $>0.001$ \\
\hline \multicolumn{4}{|l|}{ Provision of staff-led organised play } \\
\hline None (Ref) & - & - & - \\
\hline$(\leq 29 \mathrm{~min})$ & 1.4 & $(0.88,2.16)$ & 0.157 \\
\hline$(\geq 30 \mathrm{~min})$ & 2.3 & $(1.47,3.83)$ & $>0.001$ \\
\hline \multicolumn{4}{|c|}{ Active games that engage the majority of children to participate } \\
\hline No (Ref) & - & - & - \\
\hline Yes & 1.7 & $(1.11,2.61)$ & 0.015 \\
\hline \multicolumn{4}{|c|}{ Active games where children stood still in lines and waited their turn to participate } \\
\hline No (Ref) & - & - & - \\
\hline Yes & 1.1 & $0.67,2.05$ & 0.567 \\
\hline \multicolumn{4}{|c|}{ Active games that consist of child elimination components } \\
\hline No (Ref) & - & - & - \\
\hline Yes & 0.6 & $0.37,0.86$ & 0.008 \\
\hline \multicolumn{4}{|l|}{ Staff engage in physical play with children } \\
\hline No (Ref) & - & - & - \\
\hline Yes & 0.8 & $(0.56,1.04)$ & 0.088 \\
\hline
\end{tabular}

Clustered by OSHC service and child, adjusted for sex and age

Note: Bolded values are significant $\mathrm{P}<0.05$

games engaging the majority of children, this identifies a potential area for future intervention within the OSHC setting.

The benefits of structured staff-led organised play within childcare settings, however, have been debated within the broader literature $[20,25,26]$, with some studies reporting organised activities to have a lower association with MVPA and higher duration spent idle due to prolonged activity set-up, instructions, and the selection of games that require children to wait their turn or be eliminated from the activity if deemed "out". This has previously been attributed to a lack of effective staff physical activity training $[21,27]$. It is therefore, not surprising that our results report the odds of children 
meeting 30 min of MVPA reduced by nearly half when organised games included elimination components to their activities. Unexpectedly, no associations were found between the presence of physical activity policies, staff training or staff engagement in physical activity with children and an increase in child MVPA. This may be reflective of a lack of specific National/State-level policy or standards surrounding physical activity recommendations within the Australian OSHC setting, and the non-mandatory requirements for service-level physical activity, sedentary behaviour or screen-time policies nor staff physical activity promotion training. This also may explain the low reported number of physical activity policies, opportunities for staff physical activity training, or the limited observed engagement of staff members in physical activity with children. These results further highlight potential areas for future health promotion opportunities including the development of specific guidelines for the OSHC setting. Additionally, regardless of limited specific guidelines, recreational screentime was not overtly observed nor was it associated with reduced odds in children meeting $30 \mathrm{~min}$ of MVPA. Although recreational screen-time (including handheld devices) was reported to be available (if requested) at $30 \%$ of services; it was only observed for more than $30 \mathrm{~min}$ on $19 \%$ of days, and it was typically available after 16:30 allowing children the opportunity to be physically active for an hour before these devices became available to them.

\section{Strengths and limitations}

This study has several strengths. It is one of the first studies in Australia to use device-based measures of physical activity (accelerometry) to capture child activity levels within OSHC services and explore environmental factors associated with MVPA. Our study used validated observation tools to capture contextual data on physical activity environments and staff behaviours within a large sample of OSHC services. Several limitations must be considered; first, this study was conducted in only two Local Health Districts of NSW, and although this was a large and diverse sample, due to the inconsistency of OSHC requirements between state and territories these findings may not be generalisable outside of NSW. Secondly, there is the potential for staff and children to have modified usual behaviour due to the presence of data collectors. We attempted to reduce this risk by conducting unannounced site visits and asking services to proceed as normal. Furthermore, child activity levels, accumulated during school hours were not captured within this study, as this was beyond the scope of our research.

\section{Conclusion}

OSHC services have the potential to provide positive environments that support physical activity through play and recreation. On average children accrued nearly a quarter of their daily MVPA, with $26 \%$ meeting at least $30 \mathrm{~min}$ of MVPA while attending OSHC after school. Although this is an encouraging finding, there is the potential for OSHC services to further support children to increase levels of MVPA through play. Results from our study show this could be achieved via scheduling a minimum of $60 \mathrm{~min} /$ day for child-led free play, and incorporating opportunities for staff-led organised games for at least $30 \mathrm{~min} /$ day, several times per week. When staff lead organised games they should choose activities that engage the majority of children and exclude barriers to physical activity, such as eliminating children from the games. Future interventions should focus on staff training resources or the development of sector-specific physical activity policies/guidelines to assist staff to support children to meet daily physical activity requirements.

\begin{abstract}
Abbreviations
OSHC: Out of school hours care; NSW: New South Wales; MVPA: Moderate-tovigorous physical activity; ACECQA: Australian Children's Education and Care Quality Authority; HAAND: Healthy Afterschool Activity and Nutrition Document; SOSPAN: System for Observing Staff Promotion of Physical Activity and Nutrition; PA: Physical activity.
\end{abstract}

\section{Acknowledgements}

None

\section{Authors' contributions}

Ruth Crowe is a PhD candidate within this study, she has worked with the research team to develop the study design and methodology, led data collection, training, analysis, interpretation and write up of this manuscript. Yasmine Probst and Rebecca Stanley are PhD supervisors and co-investigators on this project. They have contributed to the funding support, study design and provided support through the development and revised the manuscript. Sarah Ryan is the project manager who has provided administrative and data analysis support as well as the revision of the manuscript. Michael Beets and Glenn Weaver contributed to the study design, methodology and training in data collection protocols. Jennifer Norman, Susan Furber, Lisa Franco, Megan Hammersley, Cecilia Vuong, Karen Wardle, Christine Innes-Hughes, and Marc Davis are a part of the Prevention Research Support Program working committee, offering valuable insight and context of local health districts. Professor Anthony Okely is the chief investigator of this study, contributing to the funding support, study design, methodologies and is a PhD supervisor on this project. All authors have read and approved the final manuscript. This manuscript has not been submitted or published in any other journal.

\section{Funding}

This research has been conducted with the support of the Australian Government Research Training Program Scholarship. This work was supported by the Prevention Research Support Program, funded by the New South Wales Ministry of Health. We declare the funding body has had no influence on the study design, data collection, analysis, interpretations of the findings or writing of this manuscript. 


\section{Availability of data and materials}

The datasets generated and analysed during the current study are not publicly available as participants did not provide informed consent for data sharing.

\section{Declarations}

\section{Ethics approval and consent to participate}

Ethics approval was granted by the University of Wollongong Human Research Ethics Committee (HE17/490). Written informed consent was obtained from each OSHC director. Due to the observational nature of this research, methods were determined as low risk and a passive consent was applied to this study.

\section{Consent for publication}

Not applicable.

\section{Competing interests}

The authors have declared there is no competing interests.

\begin{abstract}
Author details
'Early Start, Building 21, Ring Road, Keiraville, NSW 2522, Australia. ${ }^{2}$ School of Medicine, Faculty of Science Medicine and Health, University of Wollongong, Northfields Avenue, NSW, Wollongong, Australia. ${ }^{3}$ Illawarra Health and Medical Research Institute, University of Wollongong, Wollongong, NSW Australia. ${ }^{4}$ Early Start, Faculty of the Arts Social Sciences and Humanities, University of Wollongong, Wollongong, NSW, Australia. ${ }^{5}$ Exercise Science, University of South Carolina, Columbia, SC, USA. ${ }^{6}$ Health Promotion Service, Illawarra Shoalhaven Local Health District, Warrawong, NSW, Australia. ${ }^{7}$ Health Promotion Service, South Western Sydney Local Health District, Liverpool, NSW, Australia. ${ }^{8}$ Centre for Population Health, St Leonards, NSW, Australia.
\end{abstract}

Received: 11 June 2021 Accepted: 30 August 2021

Published online: 16 September 2021

\section{References}

1. Carson V, Tremblay MS, Chaput JP, Chastin S. Associations between sleep duration, sedentary time, physical activity, and health indicators among Canadian children and youth using compositional analyses. Appl Physiol Nutr Metab. 2016;41(6):294-302.

2. Biddle SJH, Ciaccioni S, Thomas G, Vergeer I. Physical activity and mental health in children and adolescents: An updated review of reviews and an analysis of causality. Psychol Sport Exerc. 2019:42:146-55.

3. Australian Institute of Health and Welfare. Physical activity across the life stages. 2018. http://www.aihw.gov.au. Accessed Jan 2021

4. Beets MW, Webster C, Saunders R, Huberty J. Translating Policies Into Practice: A Framework to Prevent Childhood Obesity in Afterschool Programs. Health Promot Pract. 2013;14(2):228-37.

5. Beets MW, Weaver RG, Turner-McGrievy G, Huberty J, Ward D, Pate R, et al. Physical activity outcomes in afterschool programs: A group randomized controlled trial. Prev Med. 2016;90:207-15

6. Beets MW, Weaver RG, Brazendale K, Turner-Mcgrievy G, Saunders R, Moore J, et al. Statewide dissemination and implementation of physical activity standards in afterschool programs: Two-year results. BMC Public Health. 2018;18(1):819.

7. Department of Education and Training. Early Childhood and Child Care in Summary. 2018. https://docs.education.gov.au/system/files/doc/other/ eccc_in_summary_jun_quarter_2018_0.pdf. Assessed Feb 2021.

8. Crowe R, Probst Y, Norman J, Furber S, Franco L, Stanley R, et al. Healthy eating and physical activity environments in out-of-school hours care: an observational study protocol. BMJ Open. 2020;10:e36397.
9. Beets MW, Weaver RG, Moore JB, Turner-Mcgrievy G, Pate R, Webster C, et al. From policy to practice: Strategies to meet physical activity standards in YMCA afterschool programs. Am J Prev Med. 2014;46(3):281-8.

10. Beets MW, Weaver RG, Turner-Mcgrievy G, Huberty J, Ward D, Pate R, et al. Making policy practice in afterschool programs: A randomized controlled trial on physical activity changes. Am J Prev Med. 2015;48(6):694-706.

11. Ajja R, Beets MW, Huberty J, Kaczynski A, Ward D. The Healthy Afterschool Activity and nutrition documentation instrument. Am J Prev Med. 2012:43(3):263-71.

12. Weaver RG, Beets MW, Webster C, Huberty J. System for observing staff promotion of activity and nutrition (SOSPAN). J Phys Act Heal. 2014;11(1):173-85.

13. Weaver RG, Beets MW, Huberty J, Freedman D, Turner-Mcgrievy G, Ward D. Physical activity opportunities in afterschool programs. Health Promot Pract. 2015;16(3):371-82.

14. Ridgers ND, Stratton G, McKenzie TL. Reliability and validity of the system for Observing Children's Activity and Relationships during Play (SOCARP). J Phys Act Heal. 2010;7(1):17-25.

15. McHugh ML. Interrater reliability: The kappa statistic. Biochem Medica. 2012;22(3):276-82.

16. Evenson KR, Catellier DJ, Gill K, Ondrak K, McMurry R. Calibration of two objective measures of physical activity for children. J Sport Sci. 2008;26(14):1557-65

17. Trost Sg, Loprinzi Pd, Moore R, Pfeiffer K. Comparison of Accelerometer Cut Points for Predicting Activity Intensity in Youth. Med Sci Sport Exerc. 2011;43(7):1360-8.

18. Tassitano RM, Weaver RG, Tenório MCM, Brazendale K, Beets MW. Physical activity and sedentary time of youth in structured settings: a systematic review and meta-analysis. Int J Behav Nutr Phys Act. 2020;17(1):1-17.

19. Riiser K, Haugen ALH, Lund S, Løndal K. Physical Activity in Young Schoolchildren in After School Programs. J Sch Health. 2019;89(9):752-8.

20. Trost SG, Rosenkranz RR, Dzewaltowski D. Physical Activity Levels among Children Attending After-School Programs. Med Sci Sport Exerc. 2008;40(4):622-9.

21. Beets MW, Weaver RG, Turner-Mcgrievy G, Moore JB, Webster C, Brazendale K. Are we there yet? Compliance with physical activity standards in YMCA afterschool programs. Child Obes. 2016;12(4):237-46.

22. Coleman KJ, Geller KS, Rosenkranz RR, Dzewaltowski D. Physical activity and healthy eating in the after-school environment. J Sch Health. 2008;78(12):633-40.

23. Ajja R, Clennin MN, Weaver RG, Moore JB, Huberty JL, Ward D. Association of environment and policy characteristics on children's moderate-to-vigorous physical activity and time spent sedentary in afterschool programs. Prev Med. 2014;69:49-54

24. Maher C, Virgara R, Okely T, Stanley R, Watson M, Lewis L. Physical activity and screen time in out of school hours care: An observational study. BMC Pediatr. 2019;19(1):283.

25. Chandler JL, Brazendale K, Drenowatz C, Moore J, Sui X, Weaver RG. Struc ture of physical activity opportunities contribution to children's physical activity levels in after-school programs. J Phys Act Heal. 2019;16(7):512-7.

26. Huberty JL, Beets MW, Beighle A, McKenzie T. Association of staff behaviors and afterschool program features to physical activity: findings from Movin'After School. J Phys Act \& Heal. 2013;10(3):423-9.

27. Weaver RG, Moore JB, Turner-McGrievy B, Saunders R, Beighle A, Khan MM. Identifying Strategies Programs Adopt to Meet Healthy Eating and Physical Activity Standards in Afterschool Programs. Heal Educ Behav. 2017:44(4):536-47.

\section{Publisher's Note}

Springer Nature remains neutral with regard to jurisdictional claims in published maps and institutional affiliations. 